3572016 Annual

Meeting

Announcement

359 Executive

Director's Report

362 APSA's Finan-

cial Operations

2014-2016

367 APSR Editor's

Report 2014-2015

372 13th APSA TLC Recap
375 2016-2017 APSA Minority Fellows

376 Briefs

385 International Programs

387 Gazette

387 Minutes of the April 2015 Council Meeting

391 APSA Committees 395 Dissertation List 112th APSA Annual

Meeting \& Exhibition

Philadelphia, PA

September 1-4, 2016
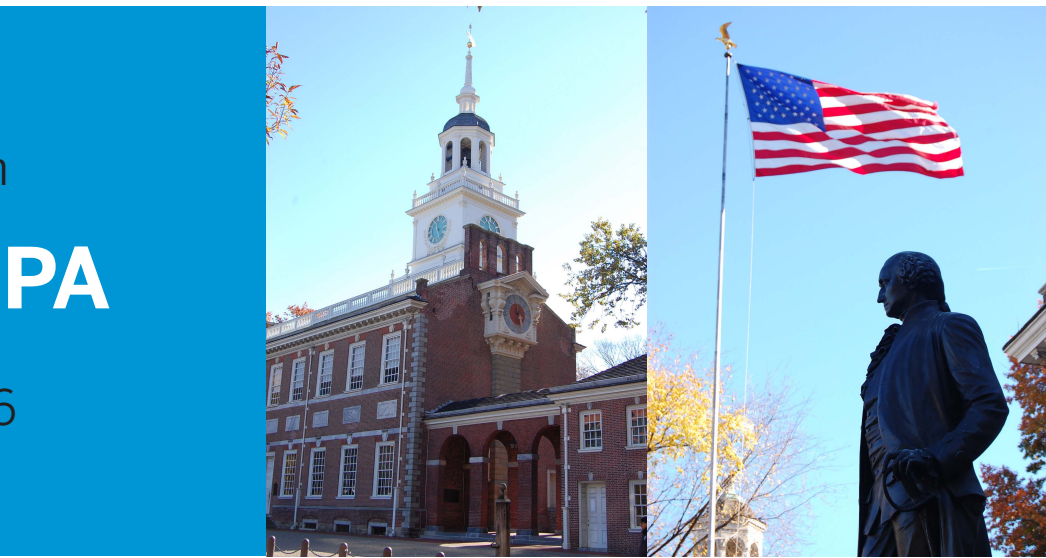

\title{
Great Transformations: Political Science and the Big Questions of Our Time
}

\author{
Heidi Souerwine, Director, Meetings and Events
}

\section{GET READY FOR PHILADELPHIA!}

Join us in Philadelphia for the 112th APSA Annual Meeting to address the latest scholarship in political science while exploring the 2016 theme, "Great Transformations: Political Science and the Big Questions of Our Time." APSA and the 2016 Program Chairs Kimberly Morgan, The George Washington University, and Deborah Schildkraut, Tufts University, look forward to your participation in panels and sessions prepared by APSA's 55 divisions and numerous related groups at the 2016 meeting.

The association brings the largest political science conference in the world to Philadelphia, the cradle of liberty, a city of firsts, and the US's first and only UNESCO World Heritage City. Although the APSA Teaching and Learning Conference has been held in Philadelphia in recent years, the Annual Meeting returns for the first time since 2006. It is home to James Beard Award-winning chefs, was named one of the most walkable cities in the nation, and was recently named the \# 1 Best City in the US by Lonely Planet, in large part due to the transformation and rejuvenation of the city center and the various neighborhoods have been experiencing in the past decade.

As the fifth largest city in the United States within 200 miles of 46 million people, Philadelphia promises to draw a large audience, so we recommend registering and booking your discounted APSA hotel early. Registration is now live! For more information, visit: http://community.apsanet.org/ annualmeeting/register/registration.

\section{CONFERENCE PROGRAM}

An anticipated 6,500 political scientists will participate in the three and half days of sessions-and the preliminary day of short courses-from which to choose. Sessions are developed by APSA sections, divisions, and related groups. The preliminary program will be available at the end of May.

In addition to the educational sessions, meeting highlights will include the presidential address by Jennifer Hochschild,
Harvard University; the opening reception; career placement; the APSA awards ceremony; APSA section and partner meetings and receptions; and an exhibit hall with more than 100 publishers, classroom software technology providers, and more.

The 2016 Annual Meeting introduces a new conference schedule. In an effort to maximize participation and expand opportunity in the field, APSA has added a fifth time slot to the Thursday, Friday, and Saturday days of the conference. By utilizing industry-wide, popular 9o-minute sessions, APSA could add this fifth time slot on these days, while also eliminating the unpopular 7:30 a.m. sessions.

Additionally, the conference cochairs introduced a wide variety of new session formats, with which the divisions and related groups could program their content. Intended to extend the onsite experience beyond didactic presentations, these new interactive session formats hope to expand opportunities for participation while also addressing member interest in more innovative formats 


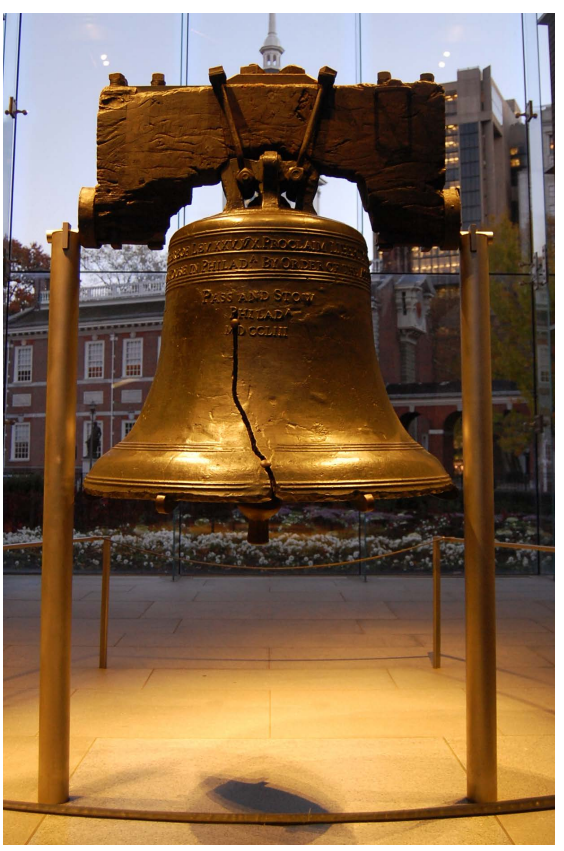

(All photos courtesy of Drew Meadows)

and additional professional development opportunities onsite.

For more information visit http:// community.apsanet.org/annualmeeting/ conference-program/schedule-at-a-glance and http://community.apsanet.org/annualmeeting/ call/proposal-options.

\section{PARTICIPATION}

After a successful call for proposals, the Annual Meeting conference cochairs have been busy planning and confirming details for approximately 40 plenaries, theme panels, and breaking-news sessions.

Proposal acceptances have been sent, and participants are confirming their participation roles. When accepting panel and individual paper proposals, it is important to follow the four 2016 participation rules:

\section{Rule 1}

Participation Limitation: Participation is limited to one (1) paper author or coauthor presentation and one nonauthor appearance, excluding discussants.

Limit 1: Author presentations in research panels and poster sessions: Participation in the Annual Meeting is limited to one (1) paper author or coauthor presentation in a paper panel session, regardless of the organizer (division, related group, conference co-chairs, etc.). Only presentations count against this participation limit. For example, an attendee may have three coauthored papers on the program and, so long as she or he is a presenter for only one of these papers (and a non-presenting coauthor in the other two), this would fall within the participation limits.

Limit 2: Nonauthor appearances in research panels, roundtables, and other session formats: Participation in the Annual Meeting is limited to one (1) appearance on the program as a panel chair OR one (1) nonauthor presentation participant in any other session format, in sessions organized by any of the following: division, APSA committee, or related group.

\section{Exemptions}

- Participation as a nonpresenting coauthor does not count against the author presentation limit.

- Participation as a discussant does not count against any appearance limits.

- Participation in a theme panel is an allowed third role/appearance.

- Participating or presenting a paper on a panel organized by Division 9: Teaching and Learning in Political Science or Division 10: Political Science Education does not count against these limits.

- If a person is appearing during a panel session as an author or coauthor presenter, serving as chair or discussant of the same session does not count against the participation limit.

- Participation in or leadership of preconference workshops or short courses does not count against the participation limit.

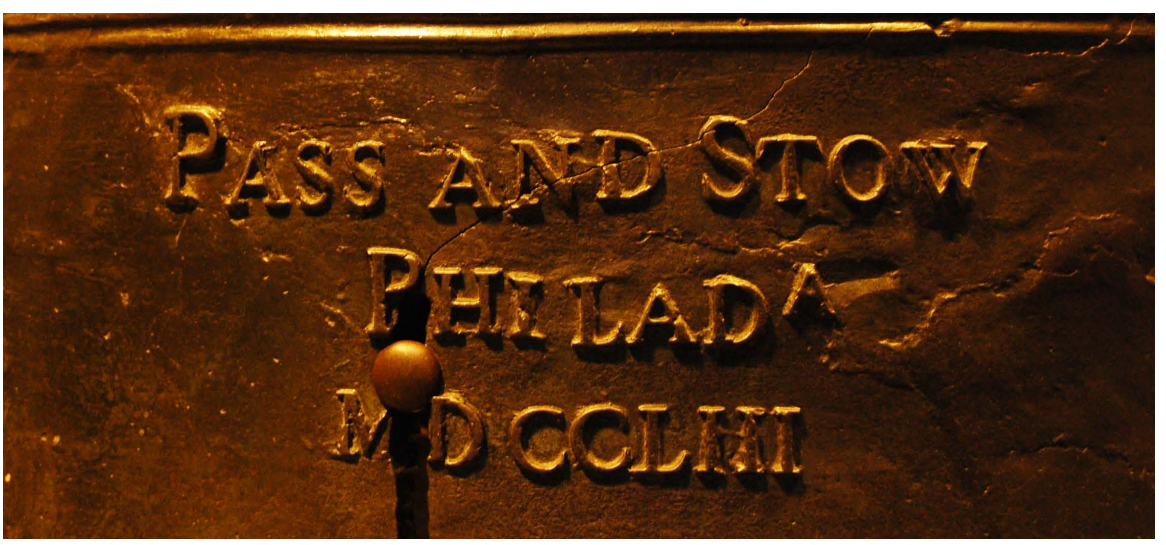

- Delivery of an e-poster presentation does not count against the participation limit.

There are no other exemptions from the participation limits.

\section{Rule 2}

Pre-registration: The APSA Council requires all program participants to preregister by June 10, 2016. Participants who do not pre-register by June 10 will be removed from the program.

\section{Rule 3}

Paper Delivery: As a paper presenter, you have an important obligation to ensure that all members of your panel, especially discussants, receive your paper two (2) weeks prior to the conference, with enough time to prepare for the meeting. Papers should be uploaded to the conference system no later than August 15, 2016.

\section{Rule 4}

Panel Schedule: Panels are scheduled in time slots beginning at 8:00 a.m. on Thursday and concluding at 12:00 noon on Sunday. Participants are expected to be available for any of the time slots. Please note that due to the large number of participants on the meeting program, scheduling requests are not accepted.

\section{TRAVEL GRANTS}

APSA provides travel grants to assist some members in attending the Annual Meeting. APSA members who are US graduate students, international graduate students studying in the United States, unemployed, or international scholars are eligible to apply. If selected, recipients must preregister for the APSA Annual Meeting to be able to receive travel grants. Priority will be given to applicants who will present at the Annual Meeting, to first-time applicants, or those who have not received a travel grant since 2014. For more information visit: http://community. apsanet.org/annualmeeting/register/ travel-grants

\section{GETTING TO PHILADELPHIA}

As the city's official convention and visitor's bureau, Discover Philadelphia's website (www.discoverphl.com) can provide great assistance for planning your trip and your time onsite. You'll find a detailed visitor's guide, a local events listing, international and domestic travel resources, interactive and printable maps, dining and shopping suggestions, and much more. 